THE INTERNATIONAL

REVIEW OF RESEARCH IN

OPEN AND DISTANCE LEARNING

\title{
Study Orchestrations in Distance Learning: Identifying Dissonance and its Implications for Distance Educators
}
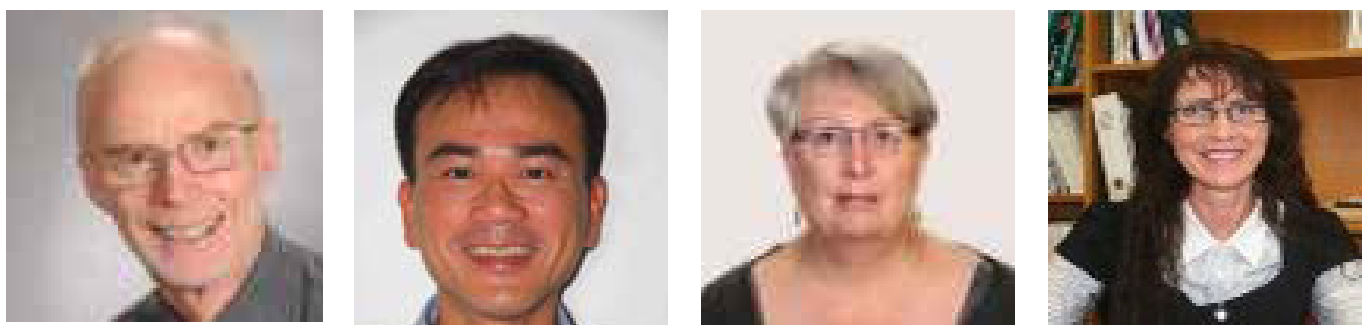

Bill Anderson, Scott W. F. Lee, Mary G. Simpson, and Sarah J. Stein University of Otago, New Zealand

\section{Abstract}

The exploration of study orchestrations emphasises students' active participation in learning, describing the ways in which they marshal the resources available to them in response to their learning environment. This study reports the identification of study orchestrations in a group of distance students and identifies the existence of dissonant study orchestrations, which previous research has linked with poor achievement, in approximately onefifth of the group. Data came from responses by 176 students to the ASSIST questionnaire. The data was subject to factor analysis to ensure commensurability with previous studies, and then cluster analysis was used to identify groups with similar study orchestrations. Four clusters were identified. One of these was clearly dissonant, pointing toward problematic links between learning environments and student approaches to study. The implications of dissonant study orchestrations are explored and further research is suggested, along with implications for the practice of distance educators.

Keywords: Approaches to study; study orchestrations; metacognition; higher education

\section{Introduction}

The exploration of student approaches to learning and studying has developed markedly since the first work was undertaken in the 1970s. Although it did not use the term approaches to study, Marton and Säljö's (1976) paper is commonly regarded as the initial work in the area. Since then, several shifts in thinking have brought about useful reconceptualisations. From the early consideration of the two main forms of learning approach-deep and surface-the area widened to consider approaches to study and incorporated the notion of a strategic approach to studying (Entwistle \& Ramsden, 1983). Understanding approaches to 
study can be useful for several reasons. A stronger call to justify public expenditure on tertiary education and to raise course completion and retention rates, especially for distance students, brings renewed focus to the importance of student study strategies. Additionally, there is evidence that teachers, and the study context they help create, have both direct and indirect impacts on the approaches to study adopted by students and on their academic achievement (Trigwell, Prosser, \& Waterhouse, 1999).

Research into approaches to study is mostly undertaken with on-campus students. Perhaps because of their relative inaccessibility, distance students have not often been sought as participants in this type of research. Richardson's (2000, 2005) work in this area and his work with colleagues Morgan and Woodley (1999) are exceptions, having focused on distance students, their approaches to study, and the relationships between approaches to study and other factors, including the academic environment and academic quality.

Recognizing the importance of how students perceive study contexts and how they combine various approaches to study has led to consideration of study orchestrations (Meyer, 1991). These contextualised patterns of engagement in learning can be theoretically interpretable, or consonant orchestrations, which demonstrate "harmonious combinations of deep approaches and positive perceptions of teaching” (Entwistle \& Peterson, 2004, p. 422), or dissonant orchestrations, which exhibit unanticipated or theoretically contradictory sets of responses. Recognition of dissonant study orchestrations has shed light on the relationship between approaches to study and study success (Meyer, Parsons, \& Dunne, 1990a).

The work reported here arises from a larger investigation concerning student support. In that larger investigation, the focus was on ways in which distance students sought cognitive and affective support for their learning beyond their courses and the institution in which they were enrolled. One area of investigation involved examining the relationship between individual study orchestrations and student-identified support mechanisms and required identification of study orchestrations within the research participants. This article reports the identification of study orchestrations and the extent of the existence of dissonant orchestrations within the research sample and discusses the implications of our findings for distance educators.

Consideration of dissonant study orchestrations within distance student populations has been neglected to date. This article provides initial evidence that dissonant study orchestrations are found within distance student populations and suggests additional study would be valuable. The first section below considers literature related to approaches to study in general and is followed by a section focusing on approaches to study in distance education. Following that, orchestrations are discussed and the topic of dissonant orchestrations is considered in more detail. Subsequently, results of a factor analysis of distance student scores on the Approaches and Study Skills Inventory for Students (Entwistle, Tait, \& McCune, 2000) and a cluster analysis based on the ASSIST data are presented and discussed. 


\section{Approaches to Study}

A number of inventories attempt to assess differences in how students study and learn. Although development of these inventories arose for different purposes and drew on differing theoretical perspectives, Entwistle and McCune (2004, pp. 8-9) suggest the inventories draw on the same three underlying dimensions: deep/meaning, surface/reproduction, and achieving/strategic approaches to study. There is argument against the need for the achieving/strategic dimension (Richardson, 2000). Despite the acknowledged empirical relationship between the achieving/strategic dimension and the deep/meaning dimension, retention of the former reflects the conceptual distinction between learning processes focused on developing understanding and self-regulation of aspects of the study process (Entwistle \& McCune, 2004). Based on these dimensions, three approaches to study are, in brief, characterised as follows: (1) a deep approach reflects an intention to seek understanding and meaning through relating ideas and using evidence; (2) a strategic approach is characterised by a focus on studying effectively in order to achieve good grades; and (3) a surface approach appears where the learner focuses on getting through the course, reproducing content by memorising and learning isolated facts. Approaches to study indicate the various ways that study intent and study process are combined.

Higher-education institutions have a responsibility to "create learning environments that promote ... deep-level learning" (Kreber, 2003, p. 59) because of the impact this has on the skills necessary for self-directed and lifelong learning. However, evidence that this is possible is inconclusive. Recent studies show both increased use of a deep-learning approach (Walker et al., 2009) and no change or a decline in deep-approach scores (Ballantine, Duff, \& McCourt Larres, 2008; Reid, Duvall, \& Evans, 2005; Struyven, Dochy, Janssens, \& Gielen, 2006) as a result of formal educational experiences designed to enhance deep learning. Attempting to account for this uncertainty, Roderiguez and Cano invoke the effect of time and report a decline in the use of a surface approach over time (2007), noting that although students may initially use a surface approach in tertiary study, they are likely to shift toward a deeper approach as they adapt to the demands of such study. However, the tendency for students to move in the opposite direction over time, that is, toward greater use of surface approaches, has also been reported (Cano, 2005; Gow \& Kember, 1990).

There are several key understandings about approaches to studying, despite the current uncertainty. Drawing from Entwistle (2000), we note the following: Approaches to study are recognised as useful constructs, but individual approaches to study are not considered to be stable across different courses. There is evidence, however, that students are somewhat consistent in their approaches. There are strong relationships between poor academic achievement and a surface approach to study, in combination with a lack of strategic regulation, and between good academic performance and a deep approach, provided assessment tasks require high levels of understanding. There is also evidence that the balance of learning processes used by students adopting a deep approach to study will change depending on the subject being studied (Entwistle \& Peterson, 2004). Finally, there is clear evidence of a relationship between teachers' approaches to teaching and students' approaches to learning (Trigwell et al., 1999), such that an information transmission approach to teaching is 
strongly associated with a surface approach to study.

\section{Approaches to Study in Distance Education}

Following earlier studies involving distance students, Richardson, Morgan, and Woodley (1999) undertook a major study of approaches to studying in distance education. Their findings can be summarised as follows: (1) distance students are commensurable with campus-based students in terms of their approaches to studying; (2) distance students are more likely to adopt approaches to study that more closely correspond with the espoused aims of higher education; (3) gender, age, and academic discipline impact the study approach of distance students; and (4) study approach is related to pass rates and final grades (a surface approach is negatively related to these measures) but not to course completion. These bare statements of findings require expansion.

First, the commensurability finding refers primarily to a similarity between the factor solution obtained by Richardson, Morgan, and Woodley (1999) and that from a study by Harper and Kember (1986) but also notes similarities with work by Meyer and Parsons (1989). This work showed that factor solutions of the Approaches to Study Inventory (Ramsden \& Entwistle, 1981) for both campus-based and distance students provided evidence of a meaning orientation (aligned with a deep approach) and a reproducing orientation (aligned with a surface approach), as well as two additional but less consistent factors. Second, the finding that distance students adopt approaches to study that are more aligned with the goals of higher education is likely to arise from differences between distance and on-campus students, especially with regard to age.

Richardson, Morgan, and Woodley (1999) note the tendency for distance and on-campus students to differ markedly in age distribution (older compared with younger). They cite Richardson (1994) as providing evidence to suggest that older students, studying either by distance or on-campus, are more likely to use a deep approach to study and less likely to use a surface approach to study than younger students are. The third finding relates to the impact of background variables on approaches to study. In particular, approaches to study can vary according to the academic discipline being studied, and contextual variables such as academic discipline, prior education, and even departmental contexts impact gender differences in study approach. Finally, the lack of a relationship between course completion and study approach highlighted the importance of contextual and demographic variables (such as workload and prior education) to student retention.

Since this major 1999 study, other studies exploring aspects of distance students' approaches to study have been undertaken. Murphy and Tyler (2005) moved beyond the classroom to consider how the learning approaches of part-time distance students studying management while employed influenced the transfer of learning to the workplace. The study's major finding was that "adoption of a deep approach to studies ... was associated with high rates of transfer of learning to the students' workplaces" (Murphy \& Tyler, 2005, p. 466). The authors argue that transfer is promoted because a deep approach is more likely to lead to generalisations and the formation of abstractions, both of which are important for transfer to occur. 
In 2000, Carnwell investigated relationships among approaches to study, learning styles and strategies, and materials design and how these impacted students' need for distance learning support. The study was qualitative in nature, involving interviews with 20 female distance students undertaking nursing studies. Through analysis using grounded theory techniques, Carnwell identified three approaches to study, which she labelled systematic wading, speedy-focusing, and global dipping. These approaches were seen to be closely aligned with the more common terms for approaches (deep, strategic, and surface, respectively). Beyond this, Carnwell argues that the use of a particular approach to study "is mediated by the learning context and materials design" (p. 139) and that the resulting combination of factors determines the guidance and support required by students. Lyall and McNamara (2000) also report on the impact of issues such as physical space, time available to study, time of study, and family commitments on the study approaches of distance students and note how important it is to understand combinations of factors rather than to focus on a single aspect. These studies show how students orchestrate approaches to study and other factors as responses to their learning contexts.

\section{Study Orchestrations}

The term study orchestration was introduced by Meyer to represent the idea that the combination of study approaches at an individual level is a "context-specific response that is affected by the qualitative level of perception of certain elements of learning context" (Meyer et al., 1990a, p. 70). Thus, individuals may orchestrate their approaches to study differently in any particular learning context. In 1991, in a paper written to provide the conceptual and empirical basis for the concept, Meyer defined study orchestration as "the contextualised study approach adopted by individual students or by groups of students" (p. 297). The exploration of study orchestrations emphasises students' active participation in learning, describing the ways in which they marshal the resources available to them in response to their learning environment (Lindblom-Ylänne, 2003).

Early studies by Meyer, Parsons, and Dunne (1990a; 1990b) provided evidence that academic success was associated with theoretically interpretable study orchestrations, that is, study orchestrations in which there is consonance "between how the context and the content of learning are perceived and how learning takes place” (Cano, 2007, p. 135). However, most attention has been focused on the concept of dissonant orchestrations, described by Meyer (2000, p. 5) as occurring when "the expected theoretically coherent linkages between some or all of the more common sources of explanatory variation in contextualised learning behaviour fail to appear in a readily recognisable and interpretable form."

Dissonant study orchestrations can arise for several reasons (Long, 2003). Long argues that reasons for students to adopt such orchestrations include lack of method in study, poorly developed metacognitive skills, and failure to react appropriately to new educational contexts (p. 34). Support for this comes from Vermunt and Verloop (2000), who identified five ways in which dissonant orchestrations could be manifested, while recognising that these ways need not be independent of one another. They describe these ways as follows: (1) students may not differentiate between ways of processing materials or regulating their 
learning - they may lack the metacognitive knowledge and awareness to do so; (2) there is a lack of fit between the strategies a student wants to use and the learning strategies fostered by the learning environment; (3) students may use processing or self-regulation strategies that are incompatible or conflicting; (4) students may use a "bare" version of a learning style, omitting essential elements; and (5) advanced or adult students in particular may aim to apply their knowledge directly but lack an appropriate learning strategy to support that aim (pp. 85-86).

Several of these manifestations of dissonance have been reported in other studies. Lindblom-Ylänne and Lonka (1999) studied a group of advanced medical students and found that those who showed dissonant study orchestrations explained that the learning environment forced them to study in a way not typical of them (p. 15). Cliff's (2000) work with educationally disadvantaged students showed that dissonant study orchestrations can arise from a lack of metacognitive awareness or from the inadequate or inappropriate use of self-regulation strategies. Difficulties in the use of metacognitive skills were also reported for students with clearly dissonant study orchestrations, both by Lindblom-Ylänne (2003) and by Cano (2007), in a study of high-school students. In addition to these factors, studies have shown that dissonant study orchestrations have been associated with low study success (Cano, 2007; Entwistle, Meyer, \& Tait, 1991; Lindblom-Ylänne \& Lonka, 1999).

Dissonance, then, points toward problematic links between learning environments and student approaches to study. Some students may lack the means or ability to craft the orchestrations of their study approaches to suit their learning environment. Long (2003) argues for the "alleviation of the condition of small but significant numbers of poorly attaining students" (p. 34) who can be identified with dissonant study orchestrations and says this is an important challenge to higher education. Identification of dissonance is achievable, and there is some evidence that it may be possible to design study support that helps students overcome that dissonance (Cano, 2007; Lindblom-Ylänne \& Lonka, 1999; Wisker, Robinson, Trafford, Creighton, \& Warnes, 2003).

\section{The Present Study}

The present study examines study orchestrations in a group of distance students. Given the evidence of links between study orchestrations and student achievement, it is important to determine the existence of and the balance between the study orchestrations manifested within a distance student population. Research involving on-campus students suggests the proportion of students with dissonant study orchestrations is relatively small (typically less than $10 \%$ ), but recent research by Lindblom-Ylänne (2003) found that $23 \%$ of a group of law students had clearly dissonant study orchestrations. As noted earlier, no previous studies have attempted to identify dissonant study orchestrations within groups of distance students, and there is no indication of the extent to which they might occur in such groups. This study provides an initial response to both questions. 


\section{Method}

Two hundred and sixty-three distance students from a dual-mode university were sent a questionnaire by post. The sample was drawn from the entire population of distance students enrolled during the first semester of an academic year $(N=1,609)$. The distance student population ranged from first-year students to those undertaking doctoral coursework, although over two-thirds were studying for a postgraduate qualification. Over 90\% were studying part-time.

Participants were sent a version of the ASSIST questionnaire (Approaches and Study Skills Inventory for Students) (Entwistle et al., 2000), which had been modified for use with distance learners. The modifications for distance learners followed the example by Richardson, Morgan, and Woodley (1999), where terms or words relevant to on-campus education were replaced by the equivalents for distance learners. Sections of the ASSIST reported in this study are the 52-item study approaches questionnaire, the "Conceptions of learning" section, and the "Preferences for course and teaching" section, for each of which students were asked to rate items on a scale from 1 to 5 . Initial analysis using the "Conceptions of learning" scales gave a factor solution in which the two scales formed a factor with communality values that exceeded 1. A forced three-factor solution was difficult to interpret. The two scales were excluded from further analysis, resulting in an interpretable factor solution.

In addition, participants were asked to provide a small set of data comprising a broad field of study (health sciences, humanities and social sciences, sciences, commerce), level of study (undergraduate or postgraduate), an indication of experience with distance learning (none, 1-3, or 4 or more papers passed previously), number of hours worked, and gender. All data analysis was undertaken using the statistical analysis software package SPSS 18.

The study received ethical approval from the Human Ethics Committee of the authors' institution. All participants were involved voluntarily and gave their informed consent following receipt of information about the study. They received feedback on responses to the ASSIST survey and with that feedback were advised to contact the researchers if they required additional information or advice.

\section{Results and Discussion}

From the sample of 263 students, 178 usable responses were received, giving a response rate of $67.7 \%$. Within the group of participants, $77.4 \%$ were female and $22.6 \%$ male, reflecting the gender distribution of the population of distance students at the university from which the sample was drawn. In terms of fields of study, the distribution was as follows: Health Sciences, 43.2\%; Humanities and Social Sciences, 44.9\%; Sciences, 8.5\%; and Commerce, $3.4 \%$. This distribution slightly underweighted the percentage of Health Sciences students and slightly overweighted the percentage of Humanities students in comparison with the full distance student population. Percentages of postgraduate (78.5\%) and undergraduate 
(21.5\%) were a good match to population percentages. With regard to level of experience with distance learning, $27.1 \%$ of students reported no previous distance learning experience, $35.6 \%$ reported some experience (1-3 papers completed), and the remainder (37.3\%) were reasonably experienced distance learners having completed 4 or more distance papers previously. Of the participants, $83.5 \%$ were employed to some degree, with $55.4 \%$ reporting that they worked 37.5 hours or more per week, effectively being employed full-time.

Results are reported as follows: The first subsection reports the results of a factor analysis of the ASSIST data. The factor analysis was undertaken to ensure that ASSIST results from this group of students were commensurate with those obtained in previous studies. The second subsection reports on a hierarchical cluster analysis used to cluster participants into groups exhibiting similar study orchestrations. Cluster analysis classifies individuals according to patterns of scores-in this case, scores from the ASSIST instrument-and identifies subgroups with qualitatively different patterns of scores on the ASSIST subscales. A subsequent small subsection reports on relationships between the cluster groups and the small range of additional data gathered. Discussion of results is integral to this entire section.

Missing data appeared to be randomly scattered throughout the sample and were at a low level. Missing data in items of the ASSIST instrument (31 item scores missing) were replaced with sample means for each item. Two cases were identified as multivariate outliers with $p<.001$ and were deleted, giving a total of 176 cases used in subsequent analyses.

\section{Factor Analysis}

A preliminary principal components analysis using the thirteen subscales of the ASSIST questionnaire and the two "Preferences for courses and teaching" scales identified three principal components. This was confirmed by Catell's "scree test" (Tabachnik \& Fidell, 2007). A factor analysis was then undertaken using maximum likelihood extraction and resulted in a three-factor solution. The extracted factor matrix was subject to oblimin rotation with delta set at zero. The three-factor solution explains $49.5 \%$ of the variance. Factor loadings from the pattern matrix and Cronbach's alpha for each of the variables used are shown in Table 1. 
Table 1

Factor Loadings and Cronbach Alpha for ASSIST Subscales and Correlations between Factors

\begin{tabular}{|c|c|c|c|c|}
\hline \multirow{2}{*}{ Scale } & \multicolumn{3}{|c|}{ Factor } & \multirow{2}{*}{ Alpha } \\
\hline & \multirow[t]{2}{*}{1} & \multirow[t]{2}{*}{2} & \multirow[t]{2}{*}{3} & \\
\hline Deep Approach & & & & .85 \\
\hline Seeking Meaning & .77 & .11 & .01 & .68 \\
\hline Relating Ideas & .75 & -.15 & -.16 & .65 \\
\hline Use of Evidence & .76 & -.08 & .09 & .45 \\
\hline Interest in Ideas & .56 & .05 & -.30 & .68 \\
\hline Strategic Approach & & & & .84 \\
\hline Organised Studying & -.02 & .77 & -.03 & .49 \\
\hline Time Management & -.11 & .89 & -.08 & .78 \\
\hline Alertness to Assessment Demands & .19 & .31 & .33 & .67 \\
\hline Achievement Motivation & .06 & .74 & -.19 & .63 \\
\hline Monitoring Effectiveness & .48 & .32 & .18 & .50 \\
\hline Surface Apathetic Approach & & & & .85 \\
\hline Lack of Purpose & -.05 & -.25 & .59 & .70 \\
\hline Unrelated Memorising & -.16 & -.06 & .64 & .60 \\
\hline Syllabus Boundness & -.18 & -.14 & .49 & .71 \\
\hline Fear of Failure & .06 & -.15 & .66 & .80 \\
\hline \multicolumn{5}{|l|}{$\begin{array}{l}\text { Preference for Courses and Teaching } \\
\text { that }\end{array}$} \\
\hline Encourages Understanding & .43 & -.02 & -.35 & .70 \\
\hline Transmits Information & -.03 & .22 & .60 & .66 \\
\hline Correlations between factors & 1 & 2 & 3 & \\
\hline Factor 1 (Deep) & 1.00 & & & \\
\hline Factor 2 (Strategic) & .32 & 1.00 & & \\
\hline Factor 3 (Surface Apathetic) & -.24 & -.05 & 1.00 & \\
\hline
\end{tabular}

Note: Factor loadings with an absolute value greater than .40 are shown in bold. 
Factor loadings describe the contribution of each variable to the factors. Tabachnik and Fidell (2007) cite Comrey and Lee (1992) as suggesting that loading values of .45 can be described as fair, with loadings above .71 being described as excellent.

The pattern of factor loadings in Table 1 confirms that of earlier ASSIST analyses. Factor 1 represents the Deep Approach factor, Factor 2 the Strategic Approach, and Factor 3 the Surface Apathetic Approach. There was a positive correlation between the Deep Approach and Strategic Approach factors, but there were smaller negative correlations between Surface Apathetic and both Deep and Strategic factors. This pattern of correlations between these three factors has been found before (Entwistle et al., 2000; Richardson, 2005).

Two points of interest arise regarding the subscales in the Strategic Approach. First, the subscale "Alertness to assessment demands" does not have a high loading on any factor. The major loadings for this subscale were .31 on Factor 2 and .33 on Factor 3. Second, the subscale "Monitoring effectiveness" primarily loads onto Factor 1. Its loading for Factor 2 was .32. Both of the issues with the Strategic Approach subscales have been reported previously. The "Alertness to assessment demands" subscale was reported by Long (2003) as behaving anomalously. Byrne, Flood, and Willis (2004) note the subscale does not load on factors as expected and cite Diseth (2001) as reporting a similar finding. The cross-loading of the "Monitoring effectiveness" subscale is expected, having been reported by Entwistle et al. (2000) and described as "entirely understandable in conceptual terms" (p. 37).

The factor analysis confirms that it is appropriate to use the ASSIST instrument with this sample of distance students. Subscale loadings on the three factors are in accord with previous research, appropriate alpha coefficients are seen to exist, and factor correlations exhibit the same pattern noted in previous research.

\section{Cluster Analysis}

In this study, cluster analysis was used to group participants into a small number of sets. The sets were based on the similarity of the combination of each participant's scores on the five scales-three relating to study approach (deep, strategic, and surface-apathetic) and two relating to preferences for courses and teaching (encourages understanding and transmits information)-used in the factor analysis. Scores were standardised to ensure common variability among the different scales. A hierarchical cluster analysis was undertaken. There are many clustering algorithms available. The method chosen was the furthest-neighbour method (also known as complete linkage clustering), and the metric used was the cityblock metric. The choice was based on the finding by Overall, Gibson, and Novy (1993) that this combination enabled the best recovery of population cluster characteristics. The number of clusters identified was based on differences in agglomeration coefficients. Differences between successive changes in the agglomeration schedule were small until four clusters were reduced to three, indicating that four clusters were present.

The cluster analysis provides the statistical argument that these clusters are different. A multivariate analysis of variance was considered as a means of confirming the statistical significance of mean differences among clusters but was not used. When checking the as- 
sumptions for MANOVA use with this data, the test for homogeneity of covariance matrices (Box's test) was found to be significant and so a MANOVA was not undertaken. To determine differences between variables, multiple ANOVAs with adjusted significance levels were undertaken for those dependent variables (DVs) that met the assumption of homogeneity of variance. One dependent variable, the scale for "Course encourages understanding,” was excluded from this analysis as Levene's test for this DV was significant. Table 2 shows the mean standardised scores for each of the clusters on the five scales and provides the results of this analysis. Differences between pairs of means in the same column that are not significant at $p<.01$ in a Games-Howell comparison are marked with the same superscript.

Table 2

Mean Standardised Scores (and Standard Deviations) of Students in Four Clusters

\begin{tabular}{lccccc}
\hline & Deep & Strategic & $\begin{array}{c}\text { Surface- } \\
\text { apathetic }\end{array}$ & $\begin{array}{c}\text { Course } \\
\text { encourages } \\
\text { understanding }\end{array}$ & $\begin{array}{c}\text { Course } \\
\text { transmits } \\
\text { information }\end{array}$ \\
\hline Cluster 1 $(n=38)$ & $-0.43^{\mathrm{a}}$ & $-0.52^{\mathrm{a}}$ & $-0.22^{\mathrm{a}}$ & -0.10 & $-0.45^{\mathrm{a}}$ \\
& $(0.66)$ & $(0.63)$ & $(0.68)$ & $(0.50)$ & $(0.75)$ \\
Cluster 2 $(n=47)$ & $0.43^{\mathrm{b}}$ & $0.56^{\mathrm{b}}$ & $0.30^{\mathrm{a}, \mathrm{b}}$ & 0.35 & $0.73^{\mathrm{b}}$ \\
& $(0.70)$ & $(1.10)$ & $(0.93)$ & $(0.74)$ & $(0.48)$ \\
Cluster 3 $(n=45)$ & $-0.85^{\mathrm{a}}$ & $-0.39^{\mathrm{a}}$ & $0.76^{\mathrm{b}}$ & -1.17 & $0.56^{\mathrm{b}}$ \\
Cluster 4 $(n=46)$ & $(0.83)$ & $(0.87)$ & $(0.91)$ & $(0.84)$ & $(0.67)$ \\
& $0.80^{\mathrm{b}}$ & $0.22^{\mathrm{b}}$ & -0.87 & 0.85 & $-0.84^{\mathrm{a}}$ \\
& $(0.58)$ & $(0.94)$ & $(0.60)$ & $(0.41)$ & $(0.84)$ \\
\hline
\end{tabular}

Differences between pairs of means in the same column with the same superscript are not significant at $\mathrm{p}<.01$ in a Games-Howell comparison. Other pairs in the same column are significantly different.

The four clusters can be generally interpreted as follows: Cluster 4 is strongly associated with students adopting a deep approach in combination with very low scores on the surface-apathetic approach. These students prefer courses that encourage understanding in strong contrast with their much weaker level of preference for courses that transmit information. In contrast, students in Cluster 3 are more likely to adopt a surface-apathetic approach with only weak scores for the strategic approach and much weaker scores for the deep approach. Cluster 3 students have a strong preference for courses that transmit information. Cluster 2 scores suggest the adoption of a strategic approach. Students in this cluster scored moderately highly across all scales but with the highest score in the strategic approach scale. They are differentiated from Cluster 4 by the surface-apathetic scale and a stronger preference for courses that transmit information. The profile of Cluster 1 students is aberrant with mean scores in all scales being below the overall sample average. The lack of discernible theoretical fit suggests the existence of a group of students for whom dissonant study orchestrations are evident. 
Cluster 1, the cluster of students with dissonant study orchestrations, represents just over one-fifth of the sample. The extent of this cluster is consistent with the findings in a study by Lindblom-Ylänne (2003), in which nearly a quarter of the participants were found to have dissonant study orchestrations.

Analyses were undertaken based on the additional data: level of study, broad field of study, distance learning experience, level of employment (taken as two levels-35 hours or more of paid work and less than 35 hours of work or not employed), and gender. The only significant variation between clusters was found for level of study $\chi^{2}(3)=14.49, p<.01$ where postgraduate students were more likely than undergraduate students to be represented in Cluster 4. Age data were not gathered for the sample, so the possibility that this significant finding is an artefact of age differences between postgraduate and undergraduate students (Richardson, Morgan, \& Woodley, 1999) cannot be ruled out, even though the age profile for the distance student population at the target institution is strongly biased toward older students.

These findings provide evidence for the existence of learners with dissonant study orchestrations within the population of distance students. The presence of such a group deserves recognition because of the previously cited link between dissonant study orchestrations and low study success. The lack of apparent relationship between study orchestration and the additional data gathered supports Long's argument (2003, p. 33) that "dissonance operates in the micro-environment of the individual learner rather than arising simply from collective student disengagement from inappropriately operating curricula." In other words, change in a curriculum or teaching approach alone, often cited as a means to move students toward a study orchestration affording greater likelihood of study success (Ballantine et al., 2008; Maguire, Evans, \& Dyas, 2001; Reid et al., 2005; Walker et al., 2009), may be necessary but not sufficient to do so.

The development of metacognitive and self-regulatory skills is an important aspect of the micro-environment of the individual learner. Entwistle and McCune (2004) have reported that recent work on approaches to studying has "emphasized self-conscious reflection on studying, drawing on the ideas of metacognition and self-regulation” (p. 333). Cliff (2000) and Lindblom-Ylänne (2003) indicate the potential role of metacognitive skills for students identified as having dissonant study orchestrations. Anderson (2007) also identified the importance of metacognitive strategy use in distance education but noted the relative lack of studies in this area and suggested that an increasing awareness of the metacognitive strength of students was essential. Since then there has been more work with a focus on the identification and promotion of metacognitive and self-regulatory skills in distance and online learning environments (e.g., Downing, Cheung, Wong, \& Shin, 2007; Murphy, 2008; Reingold, Rimor, \& Kalay, 2008; Topcu \& Ubuz, 2008). Such skill development includes helping learners to focus attention, to monitor their learning through elaboration, and to review attainment of learning goals. However, as with curriculum change, metacognitive skill development may not be sufficient to prompt change from a dissonant study orchestration if the teaching approach or the curriculum is not also designed to support such a change. 
Limitations in this study include its relatively small sample and the high proportion of postgraduate students in the population of the institution from which the sample was drawn. Further research in different contexts is needed to confirm the existence of groups of students with dissonant study orchestrations in distance education settings. Such research would also confirm the size of such groups as a proportion of distance student populations. Given the research findings in on-campus settings, it is likely that such confirmation will occur. Educators could then focus, with renewed vigour, on the reasonably well-understood but perhaps not well-implemented work of enhancing student metacognitive awareness and skills and on ensuring that curriculum design and teaching approaches support effective and successful approaches to study in distance education.

\section{Conclusion}

This study has provided evidence for the existence of a group of students with dissonant study orchestrations within a population of distance students and has shown that that group of students comprises a reasonable proportion of the overall population. Previous work has shown that students with dissonant study orchestrations are likely to be poorly attaining students. Such students can be identified, and the evidence to date suggests that incorporating ways to develop metacognitive and self-regulatory skills and their use within distance courses is possible and would be valuable. Metacognitive development should not stand alone. In conjunction with appropriate curriculum and teaching approaches, metacognitive skill development may work to engender study orchestrations consonant with successful learning in distance education contexts. 


\section{References}

Anderson, B. (2007). Independent learning. In M. G. Moore (Ed.), Handbook of distance education (2nd ed., pp. 109-122). Mahwah, NJ: Lawrence Erlbaum Associates.

Ballantine, J. A., Duff, A., \& McCourt Larres, P. (2008). Accounting and business students' approaches to learning: A longitudinal study. Journal of Accounting Education, 26(4), 188-201.

Byrne, M., Flood, B., \& Willis, P. (2004). Validation of the approaches and study skills inventory for students (ASSIST) using accounting students in the USA and Ireland: A research note. Accounting Education: An International Journal, 13(4), 449459 .

Cano, F. (2005). Epistemological beliefs and approaches to learning: Their change through secondary school and their influence on academic performance. British Journal of Educational Psychology, 75, 203-221.

Cano, F. (2007). Approaches to learning and study orchestrations in high-school students. European Journal of Psychology of Education, 22(2), 131-151.

Carnwell, R. (2000). Approaches to study and their impact on the need for support and guidance in distance learning. Open Learning: The Journal of Open and Distance Learning, 15(2), 123-140.

Cliff, A. (2000). Dissonance in first-year students' reflections on their learning. European Journal of Psychology of Education, 15(1), 49-60.

Downing, K., Cheung, H., Wong, C., \& Shin, K. (2007). Thinking about thinking online. In P. Tsang, R. Kwan, \& R. Fox (Eds.), Enhancing learning through technology (pp. 27-50). Singapore: World Scientific Publishing.

Entwistle, N. J. (2000). Promoting deep learning through assessment: Conceptual frameworks and educational contexts. Paper presented at the first annual conference of the Teaching and Learning Research Programme, Leicester. Retrieved from http://www.etl.tla.ed.ac.uk/publications.html

Entwistle, N. J., \& McCune, V. (2004). The conceptual bases of study strategy inventories. Educational Psychology Review, 16(4), 325-345.

Entwistle, N. J., Meyer, J. H. F., \& Tait, H. (1991). Student failure: Disintegrated patterns of study strategies and perceptions of the learning environment. Higher Education, 21(2), 249-261. 
Entwistle, N. J., \& Peterson, E. R. (2004). Conceptions of learning and knowledge in higher education: Relationships with study behaviour and influences of learning environments. International Journal of Educational Research, 41(6), 407-428.

Entwistle, N. J., \& Ramsden, P. (1983). Understanding student learning. London: Croom Helm.

Entwistle, N. J., Tait, H., \& McCune, V. (2000). Patterns of response to an approaches to study inventory across contrasting groups. European Journal of Psychology of Education, 15(1), 33-48.

Gow, L., \& Kember, D. (1990). Does higher education promote independent learning? Higher Education, 19, 307-322.

Harper, G., \& Kember, D. (1986). Approaches to study of distance education students. British Journal of Educational Technology, 17, 212-222.

Kreber, C. (2003). The relationship between students' course perception and their approaches to studying in undergraduate science courses: A Canadian experience. Higher Education Research \& Development, 22(1), 57-75.

Lindblom-Ylänne, S. (2003). Broadening an understanding of the phenomenon of dissonance. Studies in Higher Education, 28(1), 63-77.

Lindblom-Ylänne, S., \& Lonka, K. (1999). Individual ways of interacting with the learning environment-are they related to study success? Learning and Instruction, 9(1), $1-18$.

Long, W. F. (2003). Dissonance detected by cluster analysis of responses to the approaches and study skills inventory for students. Studies in Higher Education, 28(1), 21-35.

Lyall, R., \& McNamara, S. (2000). Influences on the orientations to learning of distanceeducation students in Australia. Open Learning: The Journal of Open and Distance Learning, 15(2), 107-121.

Maguire, S., Evans, S. E., \& Dyas, L. (2001). Approaches to learning: A study of first-year geography undergraduates. Journal of Geography in Higher Education, 25(1), 95-107.

Marton, F., \& Säljö, R. (1976). On qualitative differences in learning: I. Outcome and process. British Journal of Educational Psychology, 46, 4-11.

Meyer, J. H. F. (1991). Study orchestration: The manifestation, interpretation, and consequences of contextualised approaches to studying. Higher Education, 22(3), 
$297-316$.

Meyer, J. H. F. (2000). The modelling of "dissonant" study orchestration in higher education. European Journal of Psychology of Education, 15(1), 5-18.

Meyer, J. H. F., \& Parsons, P. (1989). Approaches to studying and course perceptions using the Lancaster Inventory: A comparative study. Studies in Higher Education, 14, 137-153.

Meyer, J. H. F., Parsons, P., \& Dunne, T. T. (1990a). Individual study orchestrations and their association with learning outcome. Higher Education, 20(1), 67-89.

Meyer, J. H. F., Parsons, P., \& Dunne, T. T. (1990b). Study orchestration and learning outcome: Evidence of association over time among disadvantaged students. Higher Education, 20(3), 245-269.

Murphy, E. (2008). A framework for identifying and promoting knowledge and control in online discussants. Canadian Journal of Learning and Technology, 34(2). Retrieved from http://www.cjlt.ca/index.php/cjlt/article/viewArticle/491/222

Murphy, S. M., \& Tyler, S. (2005). The relationship between learning approaches to parttime study of management courses and transfer of learning to the workplace. Educational Psychology: An International Journal of Experimental Educational Psychology, 25(5), 455-469.

Overall, J. E., Gibson, J. M., \& Novy, D. M. (1993). Population recovery capabilities of 35 cluster analysis methods. Journal of Clinical Psychology, 49(4), 459-470.

Ramsden, P., \& Entwistle, N. J. (1981). Effects of academic departments on students' approaches to studying. British Journal of Educational Psychology, 51, 368-383.

Reid, W. A., Duvall, E., \& Evans, P. (2005). Can we influence medical students' approaches to learning? Medical Teacher, 27(5), 401-407.

Reingold, R., Rimor, R., \& Kalay, A. (2008). Instructor's scaffolding in support of student's metacognition through a teacher education online course-a case study. Journal of Interactive Online Learning, 7(2), 139-151.

Richardson, J. T. E. (1994). Mature students in higher education: I. A literature survey on approaches to studying. Studies in Higher Education, 19, 309-325.

Richardson, J. T. E. (2000). Researching student learning: Approaches to studying in campus-based and distance education. Buckingham, UK: SRHE/Open University Press. 
Richardson, J. T. E. (2005). Students' perceptions of academic quality and approaches to studying in distance education. British Educational Research Journal, 31(1), 7-27.

Richardson, J. T. E., Morgan, A., \& Woodley, A. (1999). Approaches to studying in distance education. Higher Education, 37(1), 23-55.

Rodriguez, L., \& Cano, F. (2007). The learning approaches and epistemological beliefs of university students: A cross-sectional and longitudinal study. Studies in Higher Education, 32(5), 647-667.

Struyven, K., Dochy, F., Janssens, S., \& Gielen, S. (2006). On the dynamics of students' approaches to learning: The effects of the teaching/learning environment. Learning and Instruction, 16(4), 279-294.

Tabachnik, B. G., \& Fidell, L. S. (2007). Using multivariate statistics (5th ed.). Boston, MA: Pearson.

Topcu, A., \& Ubuz, B. (2008). Effects of the asynchronous web-based course: Preservice teachers' achievement, metacognition, and attitudes towards the course. Educational Technology \& Society, 11(3), 181-197.

Trigwell, K., Prosser, M., \& Waterhouse, F. (1999). Relations between teachers' approaches to teaching and students' approaches to learning. Higher Education, 37(1), 57-70.

Vermunt, J., \& Verloop, N. (2000). Dissonance in students' regulation of learning processes. European Journal of Psychology of Education, 15(1), 75-89.

Walker, R., Spronken-Smith, R., Bond, C., McDonald, F., Reynolds, J., \& McMartin, A. (2009). The impact of curriculum change on health sciences first-year students' approaches to learning. Instructional Science, 38(6), 707-722.

Wisker, G., Robinson, G., Trafford, V., Creighton, E., \& Warnes, M. (2003). Recognising and overcoming dissonance in postgraduate student research. Studies in Higher Education, 28(1), 91-105.

\section{Athabasca University $\mathbf{a}$}

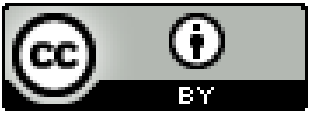

